\title{
O Discurso Parental e sua Relação com a Inscrição da Criança no Universo Simbólico dos Pais
}

The parental speech and its relation with the inscription of the child in the symbolic universe of the parents

Resumo: Neste artigo aborda-se a função constituinte do discurso parental para a inscrição da criança no universo simbólico dos pais. Através de relato sumário de dois atendimentos clínicos realizados na UTI Neonatal, aponta que a subjetividade da criança se sustenta numa rede discursiva familiar que a antecede e a determina. Ressalta assim, a importância do discurso familiar que antecede o nascimento e que se constitui como condição mínima necessária para a constituição subjetiva do infans.

Palavras-Chave: UTI Neonatal, discurso parental, bebês, psicanálise.

Abstract: In this article it is approached constituent function of the parental speech for the inscription of the child in the symbolic universe of the parents. Through summary story of two clinical assistances carried out in an neo-natal ICU, it points out that the subjectivity of the child sustains in a familiar discursive net that

\section{Michele Kamers}

Psicóloga, ex-estagiária da UTI neonatal do Hospital Santo Antônio, da cidade de Blumenau, e mestranda em Psicologia e Educação na Universidade de São Paulo - USP.

\section{Geselda Baratto}

Psicanalista e Mestre em Psicologia pela Universidade Federal de Santa Catarina - UFSC. Professora e supervisora clínica na FURB UNIVALI.

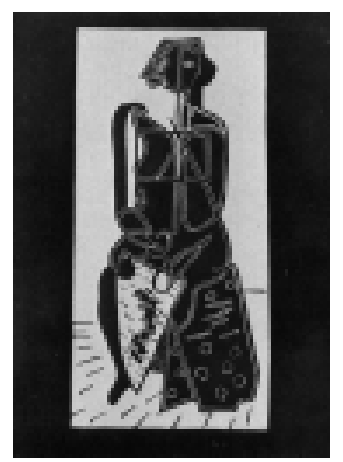
precedes it and it determines it. It standes out thus, the importance of the familiar speech that precedes the birth and that if it constitutes as necessary minimum condition for the subjective constitution the infans. Key Words: Neo-natal ICU, speech parental, babies, psychoanalysis.

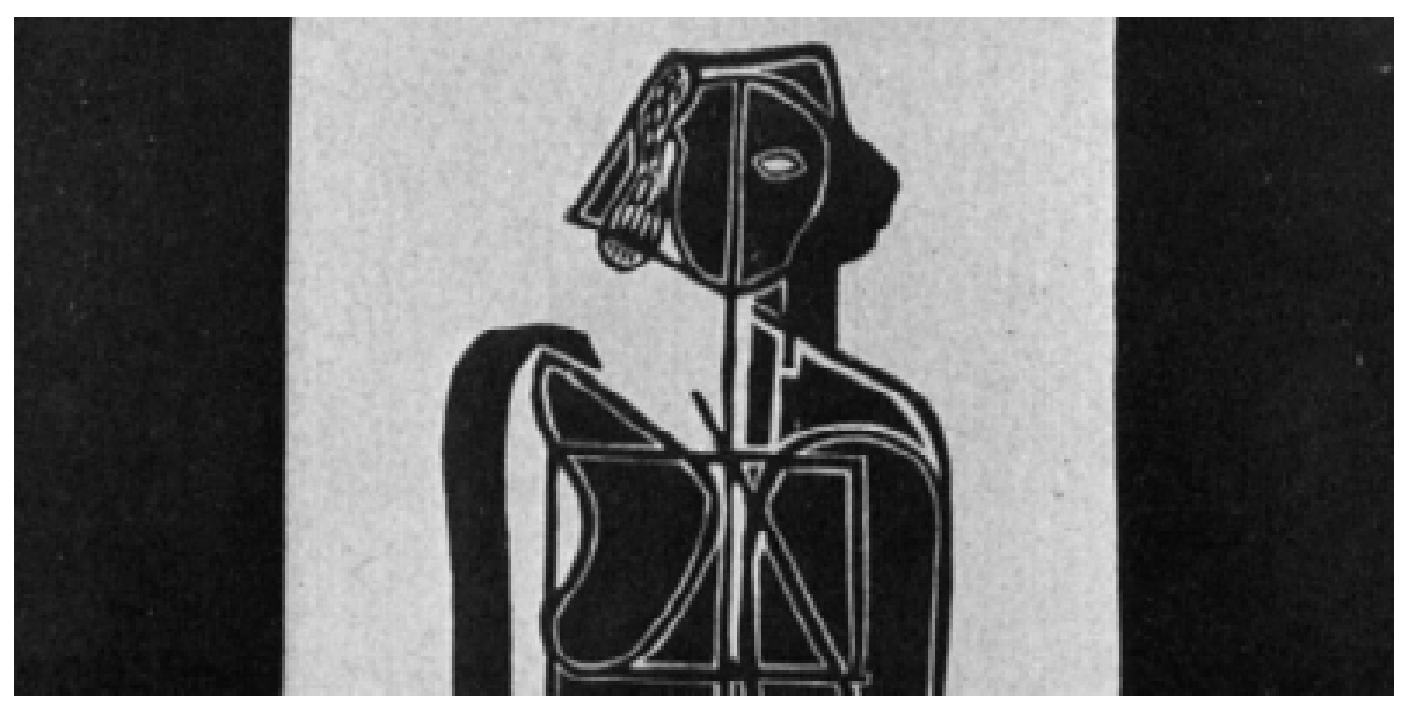

Desde a Psicanálise, sabemos que a condição para a constituição do sujeito implica a presença de um Outro Real, representante do simbólico, que encarne a função materna para o pequeno. Como nos diz Winnicott (1956) ${ }^{1}$, que coloque em cena uma certa "loucura materna", no sentido de escutar, nos gritos do bebê, pedidos endereçados ao agente materno.

A partir das formulações lacanianas, reconhecemos nessa preexistência simbólica o primeiro tempo lógico da constituição subjetiva - momento da alienação, na qual o vivente é capturado pelo desejo do Outro, sendo introduzido na matriz simbólica do casal parental. Contudo, parece-nos importante ressaltar que, antes mesmo de o vivente vir ao mundo propriamente dito, há uma préhistória que o antecede e que nele produzirá marcas constituintes de seu lugar na cultura, numa geração, numa família, em outras palavras, no simbólico, insistência veemente de Lacan no que se refere à preexistência do simbólico em relação aos registros do real e do imaginário.

Assim, a pré-história implica o lugar que os pais destinam ao futuro bebê e que está intimamente relacionado com a maternagem exercida sobre o mesmo. É algo que pode ser escutado a partir da 
escolha do nome, das fantasias dos pais e, principalmente, do discurso engendrado em torno do bebê. Referimo-nos à cadeia significante familiar que, na gravidez, será a base para a construção dos dizeres a respeito do sujeito por vir.

Ao nascer, o bebê está submetido à própria insuficiência psíquica e orgânica. $O$ nascimento do bebê não coincide com o nascimento do sujeito. Isso implica dizer que, de início, há somente um corpo "coisa", o real de um aparato orgânico constituído por reflexos arcaicos e automatismos fisiológicos, um organismo vivo que caracteriza o bebê enquanto vivente. Como nos diz Rodulfo (1990),

A questão do que é uma criança, em que consiste uma criança, conduz à pré-história, tomando-a não apenas no sentido que Ihe outorga Freud (primeiros anos de vida, que logo sucumbem à amnésia), mas à pré-história em direção às gerações anteriores (pais, avós, etc.), a história dessa família, seu folclore (...) A história da criança deixa de ser um inventário de tudo o que pode fantasiar ou não, o que conduz, por si só, a toda a problemática da pré-história, isto é, o que o precede, os modos e declives do ocorrido, determinantes para essa criança, antes que propriamente exista (p.17).

Isso se dá a partir da possibilidade subjetiva dos pais em articular seus significantes pessoais na construção da imagem do futuro bebê, da possibilidade destes em interpretar os movimentos intra-uterinos, puramente fisiológicos, utilizandoos como recursos para a construção de dizeres e imagens a respeito do "sujeito por vir".

Em se tratando de humanos, é o Outro, através de seus representantes (pai, mãe, educadora etc.), tomados aqui como função humanizante, que irá localizar o sujeito no campo da cultura humana. Referimo-nos às funções materna e paterna, que não implicam, necessariamente, a presença do pai e da mãe real - apesar de a mãe real ter recursos muito particulares para ocupar-se do bebê, pois, desde a sua condição de faltante, toma imaginariamente o filho como objeto privilegiado de seu desejo (Kamers, 2001). Conforme salienta Faria (2001),

A particularização do interesse da mãe nos cuidados que ela dedica a seu filho é o que faz do vínculo mãe-filho não apenas um vínculo fundamental, estruturante, mas estruturante na medida em que ele é único. Os cuidados maternos, aparentemente universalizáveis - a alimentação, a higiente, etc. - só têm importância na medida em que há essa particularização, na qual cada criança é marcada por um lugar específico na economia do desejo da mãe. Se não fosse assim, como seria possível à mãe supor na criança demandas, vontades, desejos e, em si mesma, a capacidade de interpretar essas supostas demandas? (p.125).

Assim, são essas funções, que, enquanto nomeantes, dão existência simbólica à criança. É através do nome próprio - puro significante que localiza o lugar do sujeito na filiação - que a criança ingressa na ordem simbólica humana (Kaufmann, 1996).

"Quer dizer que o simbólico, a linguagem, préexiste ao nascimento da criança. O sujeito préexiste ao corpo... Pré-existe, pois são os pais que, antes que a criança tenha um corpo, já o imaginam..." (Levin, 1997, p.50). O simbólico, tesouro dos significantes, antecede o sujeito. De acordo com Lacan (1964), “... a linguagem com sua estrutura preexiste à entrada que nela faz cada sujeito a um dado momento de seu desenvolvimento mental" (p.225).

Num dado momento da estruturação, o desejo implica uma possibilidade subjetiva que permite ao Outro Primordial supor algo que ainda não existe, supor um sujeito onde há somente um corpo orgânico, o que não pode ser qualificado como natural nem instintivo, pois a possibilidade de quem realiza essa função - geralmente a mãe de supor nos reflexos e automatismos do vivente um pedido de algo, depende da posição que a criança venha a ocupar na subjetividade materna.

"Sobre a criança incide um desejo, ligado ao que Lacan chama a exigência do falo pela mãe, e é em relação a esse desejo que a criança irá estruturarse. O vínculo da mãe com o filho depende, portanto, desse investimento fálico, marcado pelo lugar que a criança ocupa na economia do desejo materno" (Faria, 2001, p. 12).

A mãe, a partir de sua condição de faltante, toma o bebê como objeto privilegiado de seu desejo, o que permite a ela supor, nos gritos e choros do mesmo, uma demanda endereçada a ela. Ao escutar o choro do bebê, que em termos técnicos não passa de um automatismo fisiológico próprio à espécie, a mãe diz: "Calma, mamãe já vai te dar mamá". A mesma supõe, aí, um pedido endereçado a ela: "ele quer mamá!". Ela não diz: "Esse organismo desencadeou determinado reflexo", mas coloca o bebê como um interlocutor ativo de suas falas e atos, supondo que ele entende o que ela lhe diz.

Haveria, assim, um passo a ser dado no sentido da particularização do interesse da mãe pela criança, um passo que implica um mais-além da suposição pela mãe, da criança como ser de necessidade. Esse mais-além é o que levaria a mãe a situar-se como a

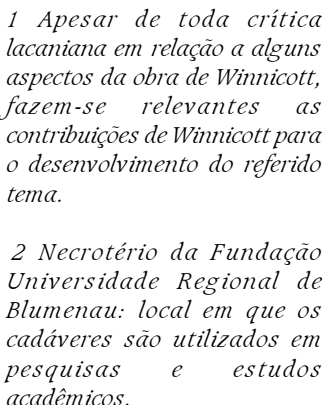


suposta detentora do sentido do choro da criança, transformando esse choro num apelo endereçado a ela (Faria, 2001, p.136), isto é, apesar de se tratar de uma função humanizadora, há que se levar em conta a posição subjetiva de quem a realiza, pois a condição sine qua non para exercê-la é o desejo. Em Psicanálise, dizemos que o bebê é capturado pela matriz simbólica do casal parental (Molina, 2001; Kamers, 2003), captura possível a partir do desejo e realizada pela função materna, representante do Outro para o bebê, já que é dela a capacidade de inscrever a lógica simbólica no corpo do mesmo.

\author{
O bebê, em sua \\ imersão primeira na \\ linguagem, seria \\ confrontado com os \\ efeitos automáticos \\ da repetição da \\ cadeia significante \\ familiar, onde \\ justamente ele é \\ situado, numa certa \\ posição de letra, a \\ partir de um \\ funcionamento \\ simbólico. Nesse caso, \\ ele estaria mais \\ particularmente \\ vulnerável a isto que \\ Lacan nomeia de \\ significante "puro", \\ mera transmissão do \\ simbólico a partir dos \\ fonemas \\ (Bernardino, 2000, \\ p.69).
}

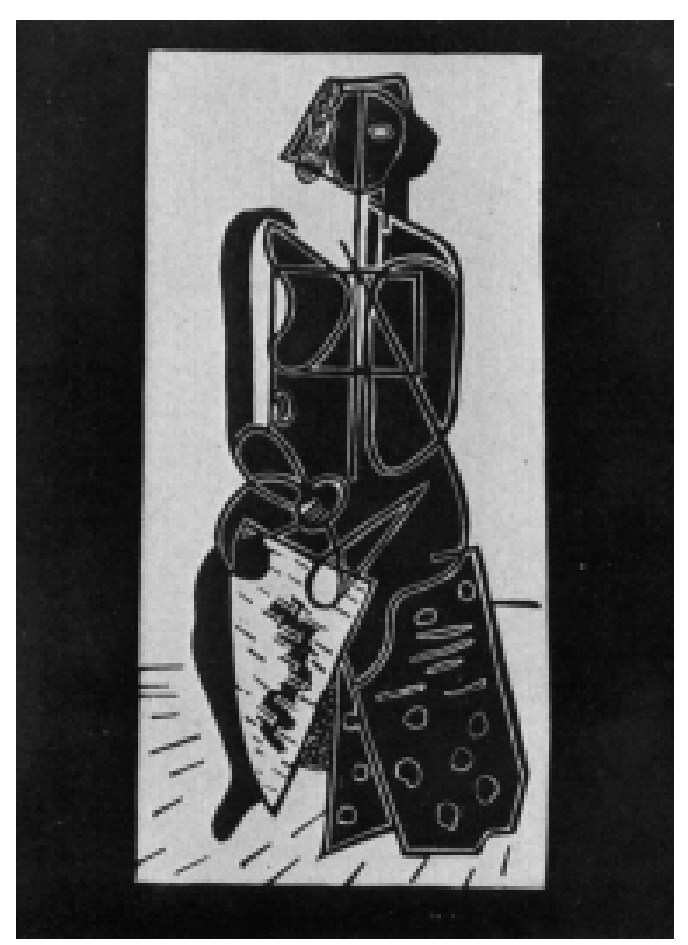

É a partir do simbólico e da singularização deste na constituição do mito familiar, dos dizeres que atravessam gerações, que os pais irão ordenar um lugar para o sujeito em questão. Nesse sentido, há que se levar em conta que essa pré-história que antecede o bebê, os dizeres que se fizeram em torno do mesmo, como no caso das características que a ele são atribuídas: "É parecido com o pai, é teimoso como a mãe etc.", o lugar que veio ocupar no fantasma parental, lugar esse dado como um "a priori" na subjetividade dos pais, será determinante na constituição subjetiva do mesmo. De acordo com Lacan, (1956) "(...) o sujeito, se parece servo da linguagem, ele o é mais ainda de um discurso em cujo movimento universal seu lugar já está inscrito desde seu nascimento, ainda que seja apenas sob a forma de seu nome próprio" (p.226).

Cabe ainda ao sujeito a tarefa de constituir sobre esses significantes a sua versão particular, o que implica dizer que há uma retomada singular dos significantes do campo do Outro por parte do sujeito - condição mesma da singularização de seu desejo.

Laznik-Penot (1999) nos lembra da importância dessa construção de um lugar "a priori", de um lugar imaginário para o bebê no psiquismo dos pais, pois, segundo a autora, é fundamental que, no confronto com o real do corpo do bebê, na constatação de sua prematuridade e de sua insuficiência tanto psíquica quanto orgânica, os pais possam, a partir dessa confrontação - bebê imaginário e bebê real - constituir um todo imaginário. Essa constituição permitirá aos mesmos envolver o organismo vivo com palavras, encontrando, no bebê real, o bebê construído imaginariamente em seu fantasma, ou seja, que nesse pequeno possam ser encarnadas essas marcas familiares, esses dizeres que o antecederam, havendo o recobrimento, pelo imaginário dos pais, do real do corpo desse bebê. Isso é algo que se dá à revelia dos próprios sujeitos envolvidos, pois opera através de uma articulação inconsciente.

Portanto, é através dos dizeres que os pais fazem em torno do bebê, da antecipação de um lugar de sujeito desejante, que este será confrontado com sua pré-história - com os significantes que o ordenaram na cadeia familiar, na medida em que estes se atualizam através da repetição de dizeres que o situam na mesma.

O bebê, em sua imersão primeira na linguagem, seria confrontado com os efeitos automáticos da repetição da cadeia significante familiar, onde justamente ele é situado, numa certa posição de letra, a partir de um funcionamento simbólico. Nesse caso, ele estaria mais particularmente vulnerável a isto que Lacan nomeia de significante "puro", mera transmissão do simbólico a partir dos fonemas (Bernardino, 2000, p.69).

No confronto com o real do corpo do bebê, é necessário que os pais possam investir libidinalmente no corpo do mesmo, situando-o no lugar imaginário construído anteriormente lugar esse que se refere à cadeia significante. Por cadeia significante familiar devemos entender o conjunto de representações recalcadas e suas sucessivas repetições, que têm como efeito ordenar discursos que atravessam gerações, permitindo aos sujeitos nela inseridos reconhecerem-se como a ela pertencentes, isto é, falar em significante implica considerar sua articulação em cadeia, já que é somente a partir desta que se faz possível um significado. "Não se trata de um significado que esgote o sentido, mas de um significante que remete a outra cadeia associativa em que está presente a questão do desejo como desejo do Outro" (Quinet, 
2000, p.40). Em outras palavras, o significado é o efeito de articulação entre dois significantes opositivos.

Com a finalidade de enfatizar a importância da pré-história do sujeito e seus efeitos de inscrição significante sobre o vivente, traremos o fragmento de dois atendimentos por nós realizados na UTI pediátrica e neonatal do Hospital Santo Antônio, na cidade de Blumenau, durante o período em que realizamos um trabalho.

Bia: pequena e valente!

Bia é um bebê prematuro com baixo peso, que se encontra internado desde o nascimento na UTI neonatal do referido hospital há quase três meses. Ao entrar no setor, esse bebê nos chama a atenção desde a primeira vez em que o vemos, pois chora demasiadamente, algo que se destaca no setor e faz com que toda a equipe se mobilize para atendê-lo.

Durante a entrevista, a mãe nos relata que, no sexto mês de gestação - período em que fazia o acompanhamento pré-natal - recebe do médico o diagnóstico de que possuía complicações gestacionais e que estas, com certeza, iriam desencadear o parto prematuramente. Asseverando, ainda, que a filha era muito pequena e, provavelmente, não sobreviveria ao nascimento, a mãe, então, nos conta que, a partir desse diagnóstico, não conseguiu mais imaginar um bebê, mas "uma miniatura" (sic).

O parto foi muito conturbado, e a mãe nos relata que, ao ver a menina, percebe que ela "(...) não ia se criar, era muito pequena (...)" (sic). Contudo, diz que a sua percepção mudou a partir do momento em que pegou o bebê no colo e percebeu que a filha, apesar de pequena, era "valente" (sic).

É interessante, pois essa associação "pequena e valente" fez eco em nosso ouvido, e, articulada com seu discurso, entendemos que se tratava de um significante, de uma representação que falava do lugar de Bia nessa família. Tratava-se de algo que a referenciava na concepção parental, pois, a partir de um dado momento da entrevista, a mãe nos relatou que estava apressada, pois o marido a esperava na recepção do hospital para irem procurar uma casa, já que, como moravam em uma cidade vizinha, haviam decidido mudar para a cidade de Blumenau com a finalidade de ficar mais perto de Bia.

Porém, algo nos chamou a atenção. Essa família não somente havia decidido se mudar como também estava, no exato momento da entrevista, com todos os seus pertences na rodoviária em busca de um lugar para ficar. Ficamos impressionada, pois, apesar de a mãe, em seu relato, contar-nos que estavam desempregados e que tinham, além de Bia, mais dois filhos, mudaram de cidade sem ao menos procurar uma casa anteriormente. Foi justamente a partir da escuta da fala destinada a Bia, articulada com a história que nos foi contada naquele momento, que pudemos perceber que se tratava de um significante dessa família, que, apesar da imensa pobreza em que vivia, era "valente" o suficiente para enfrentar a situação atual, isto é, a mãe, ao se defrontar com o real do corpo da filha, que realmente era muito pequena, recobre esse real com o significante familiar "valente". Pensamos que foi justamente essa associação - "pequena e valente" - que permitiu a essa mãe, a partir do recobrimento imaginário do real do corpo dessa "miniatura" que tinha à frente, reconhecê-la como filha - fazendo referência a ela na cadeia significante familiar.

Nesse contexto, pensamos que, para além da realidade do diagnóstico médico, foi a inclusão de Bia na cadeia significante familiar que permitiu à mãe, apesar da "miniatura" que viu à frente, investir nela subjetivamente.

A partir desse fragmento clínico, podemos falar em transmissão simbólica da cadeia significante familiar e dos efeitos desta a partir da repetição significante, como no caso de Bia que, graças à sua inserção na cadeia significante, pôde ser tomada como sujeito desejante por sua mãe: é valente!

Com isso, queremos salientar que, no que se refere à constituição subjetiva de um vivente, não se trata apenas de fazer uma investigação fenomenológica, como em uma anamnese, onde se busca saber como foi a gravidez, o parto, o nascimento etc., mas de escutar os significantes que constituem um lugar para o bebê no universo simbólico dos pais. Trata-se dos discursos que têm o poder de designar um sujeito, inclusive de decisão sobre vida e morte do mesmo, seja ela orgânica ou psíquica. Nesse sentido, é possível que, sem a referência ao desejo materno, Bia poderia não ter sobrevivido, como afirma Jerusalinsky (1999), pois o significante altera a própria mecânica do corpo.

Por outro lado, salientamos que, se tomamos a palavra "valente" como um significante, foi porque este apareceu no discurso materno fazendo referência à cadeia significante familiar, o que implica dizer que um significante não possui um significado articulado, natural e intrínseco, mas que sua significação resulta da articulação entre dois significantes, da relação do significante à cadeia discursiva à qual se refere.

Na apresentação da cadeia significante ao bebê que se dá sob a forma da antecipação subjetiva 
que nele é realizada - há um hiato, um intervalo, sendo a ausência de uma significação intrínseca ao significante que permitirá ao bebê a produção de um significado. Em Lacan, um significante jamais remete a um significado, e, sim, a outro significante. "O Outro é o lugar em que se situa a cadeia do significante que comanda tudo que vai poder presentificar-se do sujeito, é o campo desse vivo onde o sujeito tem que aparecer" (Lacan, 1964, p.194).

É a partir da apropriação significante que é feita pelo sujeito e dos efeitos de significação que dela resultam que irá constituir-se o que, em Psicanálise, designamos fantasma - a versão particular que cada sujeito faz do desejo do Outro, do material significante que a ele é endereçado.

É justamente nesse sentido que situamos a importância da pré-história que antecede o vivente, dos significantes que o localizam na ordem simbólica familiar, já que, apesar de sua significação ser dada "a posteriori" pelo sujeito, há que se levar em conta que o pequeno está suscetível aos efeitos que essa história lhe acarreta, inclusive antes mesmo de seu nascimento. Como na menção de Szejer (1997),

(...) o feto está submetido à palavra dentro do contexto de sua história, que é aquela de seus genitores, de quem, de certa forma, é a encarnação. No entanto, provavelmente ele está bastante sem defesas dentro do útero de sua mãe em relação às vicissitudes que essa história acarreta. Ora, se essa história o molda, ela também pode agredi-lo de maneira mais ou menos violenta e deixar nele as marcas de um sofrimento (...) (p.52).

A importância da pré-história reside no fato de que esta se encontra articulada à dialética de desejo dos pais, e, se é o desejo que possibilita a vida, é a própria sobrevivência do bebê que está em jogo.

Francine: um bebê que não tinha nome

Durante nosso trabalho na UTI neonatal, certo dia chegamos ao setor e percebemos que um dos leitos havia sido isolado dos outros. Aproximamo-nos e vimos o médico responsável examinando o bebê, que aparentemente estava sem vida - razão pela qual perguntamos ao mesmo sobre o ocorrido. Este nos relata que já fazia duas horas que o bebê havia falecido, pois nascera com uma infecção adquirida durante o período gestacional. Contudo, algo nos chamou a atenção nesse caso. Na ficha de identificação desse bebê que se encontrava na incubadora, estava escrito RN (recém-nascido) e o nome da mãe - Marli. Nenhum nome
Após o diálogo com o médico, soa a campainha do setor, aparecendo uma mulher que se apresentou como a "patroa" de Marli, já que a mesma havia sofrido uma cesárea e estava internada na maternidade. A chefe do setor, ao perceber que se tratava de alguém relacionado ao bebê falecido, prontamente dá a notícia do óbito a essa mulher, pedindo-nos que acompanhássemos o caso. Nesse momento, observamos que o bebê morto estava sendo encaminhado, pela auxiliar de enfermagem, ao necrotério. Ao acompanhar a auxiliar de enfermagem durante a descida até o necrotério, a "patroa" começa a contar-nos a sua versão sobre a história de Marli.

Segundo ela, Marli trabalhava em sua casa de prostituição e já havia tido três filhos e os havia doado. Continuamos escutando-a, após deixar o necrotério, enquanto seguíamos até a maternidade para nos encontramos com Marli, mãe do bebê morto.

Ao nos encontrarmos com Marli, percebemos que ela estava muito debilitada, ocasião em que nos contou que sentia muitas dores. Na entrevista com a mesma - momento em que a patroa permaneceu presente - Marli nos relata que havia engravidado durante o trabalho e que não sabia quem era o pai, dizendo-nos o seguinte: “(...) já que tinha ficado grávida, fazer o quê!" (sic). Fala-nos sobre os outros filhos, que os tinha doado, já que não tinha condições de ficar com eles.

Começamos a indagar de Marli as circunstâncias dessa última gravidez, perguntando como havia sido - não para fins de anamnese ou busca de dados relativos a esse período - mas para possibilitar um espaço a fim de que ela pudesse falar sobre sua gravidez, na medida em que, de acordo com Freud, falando, elaboramos.

Contudo, poderíamos nos questionar: Por que investigar, fazer essa mulher falar sobre sua gravidez, se o bebê já havia falecido? Como nos dizia ansiosamente sua patroa, que estava presente: “Não toca no assunto, é pior!" (sic). Nesse sentido, o que estávamos fazendo era uma aposta! Apostar que, falando, Marli poderia dar-se conta da repetição dessa série de gravidezes, dessa atualização em ato, para dar lugar à palavra, para que, em uma possível futura gravidez, ela pudesse, talvez, fazer diferente, saindo da indiferença. Mas por que indiferença?

Ela nos conta que a gravidez foi "tranqüila", que continuou trabalhando normalmente, inclusive na noite anterior ao parto. Sentia o bebê mexer, mas não the ocorreu conversar com o mesmo ou cogitar de dar-lhe um nome. Relata, ainda, que veio de um outro Estado para Blumenau, aos 13 anos de idade, devido ao falecimento dos pais, que, segundo ela, "morreram de tanto tomar" (sic). 
Não tinha nenhum parente na cidade e, desde essa época, trabalhava na "noite".

Durante a entrevista, fomos percebendo que não havia um envolvimento de Marli com esse bebê, o que nos incitou a fazer a seguinte intervenção: "Bem, sua filha nasceu e ela precisa de um nome". Mas, por que um nome? Um nome que, "Ao designar teu corpo e o lugar dele na filiação, o nome próprio se singulariza por ser um puro significante" (Kaufmann, 1996, p.372); em outras palavras, um nome que singularizasse esse bebê.

Diante de nossa indagação, Marli nos diz que não havia pensado em um nome e que não estava em condições de escolhê-lo. Sua patroa, ainda presente nesse momento, insiste com Marli, oferecendo-se para ajudar na escolha do nome. Marli se põe a pensar e diz: "Francine" (sic). Perguntamos: Por que Francine? Ela responde: "É que o nome da outra é Franciele, e fica bonito" (sic). Aqui, podemos observar como Marli associa o nome de Francine ao de Franciele, nome de sua outra filha, o que nos permite pensar que esse nome não é dado ao acaso.

Então, ao perceber que algo de nossa intervenção havia operado um posicionamento de Marli frente ao bebê, nós nos autorizamos a dar a notícia do óbito: "Então, Marli, a Francine não resistiu...". Ela, prontamente, começa a chorar e diz: "Eu já perdi meu pai e minha mãe, mas um filho eu nunca esperava perder!", embora houvesse doado os anteriores.

Assim, enquanto escutávamos Marli falar de sua dor, de sua perda, sua patroa, que tinha ido até a assistente social ver os procedimentos legais relacionados ao óbito, retorna e diz: "Olha, Marli, ou tu vai ver o bebê lá no necrotério e a gente enterra amanhã, ou tu dá para o necrotério da FURB! " " (sic). Marli, tomada por um acesso de raiva, prontamente responde: "Fuja! Fuja! Não é filho de bicho!" (sic). Teria sido a nossa intervenção um desencadeador do reposicionamento de Marli frente ao bebê morto na medida em que, ao atribuir-lhe um nome próprio - situando-o numa história familiar - decisivamente se recusa a "doar" o corpo da filha ao necrotério? Certamente.

Trouxemos esses fragmentos do atendimento realizado com Marli com o intuito de ilustrar a determinação que a pré-história tem na vida de um bebê e a forma como o fantasma materno se atualiza no momento da gestação, como pudemos observar no caso de Marli que, devido à história pessoal de abandonos e perdas, o que implica um fracasso com o simbólico, estava impossibilitada de reconhecer essa gravidez. Conforme a mesma nos conta, continuou trabalhando normalmente, e em nenhum momento pensou em um nome para a criança, isto é, a sua história de perdas se repetia no abandono dos filhos, o que a impossibilitou de fazer um acompanhamento prénatal dessa gestação, cuja infecção levou Francine a óbito.

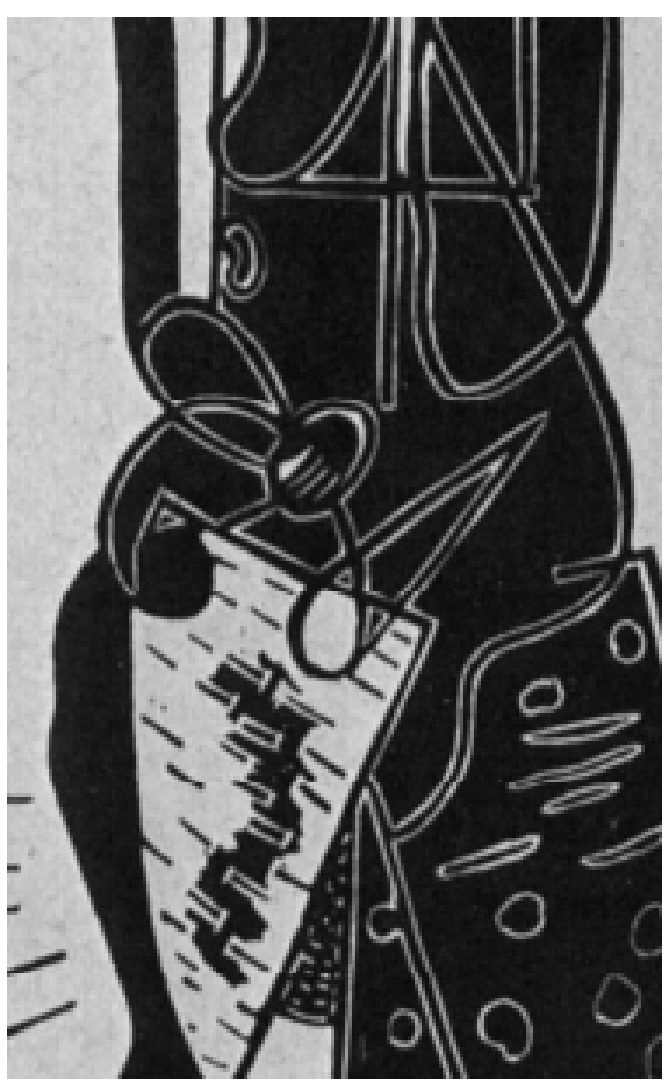

Ela, prontamente, começa a chorar e diz: "Eu já perdi meu pai e minha mãe, mas um filho eu nunca esperova perder!", embora houvesse doado os anteriores.

Nesse sentido, percebemos que Marli vinha, desde o primeiro filho, repetindo o abandono que a mesma "fantasmava" haver sofrido por parte dos pais, o que pudemos entender a partir da associação que a mesma faz diante da notícia do óbito da filha, atualizando, aí, seu próprio enredo "fantasmático".

Francine, submetida às determinações do fantasma materno - presente no fato de a mãe não poder ter reconhecido essa gravidez - nasce marcada por um não reconhecimento, o que de fato acabou provocando a sua morte, que, segundo o médico responsável, poderia ter sido evitada caso houvesse sido feito o acompanhamento pré-natal.

O que queremos salientar é que, se Marli não acolheu a possibilidade de doação do corpo da filha, dizendo "fuja, pois não é filho de bicho", é porque a mesma pôde dar um nome à criança, "nominar" esse bebê, dando existência simbólica ao mesmo. Com efeito, se isso não tivesse ocorrido, 
realmente seria filho de "bicho", apenas um organismo vivo que nasceu e morreu. Sabemos que o efeito de nossa intervenção incide efetivamente sobre a subjetividade dessa mãe.

O caso de Francine ajuda-nos a pensar o poder das palavras no que concerne a sua função simbólica de nomeação, função essa que possibilita dar existência a um sujeito antes mesmo de seu nascimento, o que, no caso de Francine, ocorreu após a morte, operando, assim, efeitos na subjetividade materna. Pensamos que é justamente nesse aspecto que reside a importância da préhistória do bebê, na medida em que é a partir dela que teremos notícias do desejo dos pais, do lugar que esse pequeno venha a ocupar no fantasma parental.
Mencionamos o caso de Francine para demonstrar como a pré-história dessa pequena já estava marcada pela tragédia da mãe. Como nos diz Bernardino (2000, p.71), "Os pais, submersos nos efeitos do significante, tornam-se impossibilitados de encarnar a função de Outro, permanecendo surdos ao seu bebê", o que implica dizer que, muito antes do nascimento, o bebê está submetido ao fantasma parental no que diz respeito aos desejos e expectativas dos genitores. Ao nascer, ele passa a habitar um mundo simbólico, um mundo construído pela linguagem, sendo através das nomeações e dizeres que os pais o antecipam; e, se a antecipação é a condição sine qua non para o advento do sujeito, é a própria subjetividade que corre o risco de se instalar, ou não!

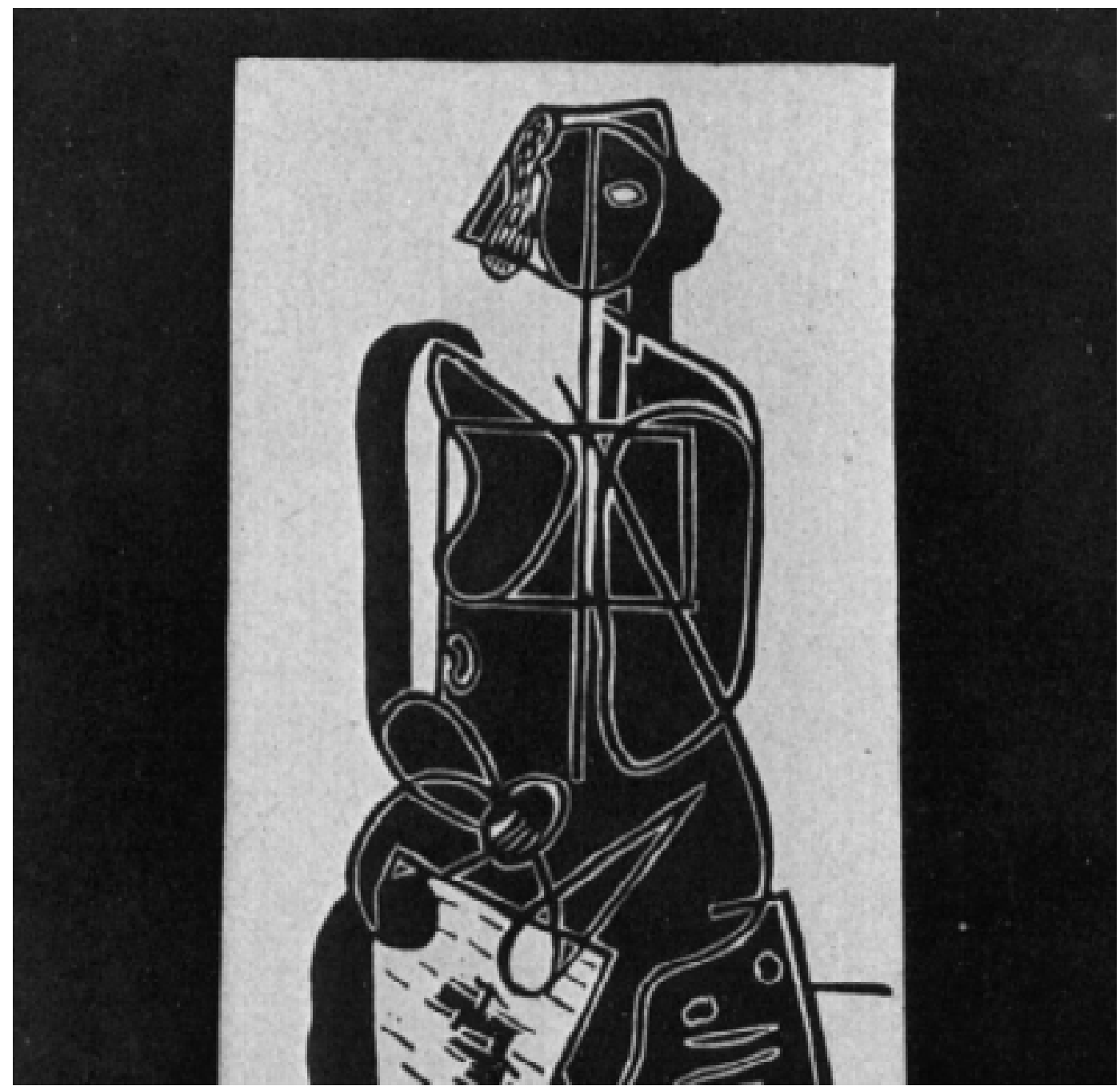


Michele Kamers \& Geselda Baratto Rua Richard Holetz $n^{\circ}$ 30. Bairro: Bom Retiro. Blumenau/SC CEP: 89010550 E-mail:michelekamers@yahoo.com.br Tel.: (47) 91024671

BERNARDINO, L. F. Bases Psicanalíticas Para uma Escuta de Bebêse de seus Pais, a Partir do Seminário Sobre "A Carta Roubada". In Revista da Associação Psicanalítica de Curitiba. Psicanálise e Clínica de Bebês. Ano IV. no 4. Publicação interna, 2000.

FARIA, M. R. A Criança e o Complexo de Édipo - do Universal Teórico ao Particular da Clínica. Tese de Doutorado. Instituto de Psicologia, Universidade de São Paulo, São Paulo, 2001.

JERUSALINSKY, A. Psicanálise e Desenvolvimento Infantil: um Enfoque Transdisciplinar. Porto Alegre: Artes e Ofícios, 1999.

KAMERS, M. O Brincar no Primeiro Ano de Vida. Trabalho de conclusão de curso. Faculdade de Psicologia. Fundação Universidade Regional de Blumenau, FURB: Blumenau, 2001.

Do "Encantamento" Necessário à Realidade de uma Construção. In Correio da Associação Psicanalítica de Porto Alegre APPOA. Porto Alegre: APPOA, no 110, ano IX, 2003.

KAUFMANN, P. Dicionário Enciclopédico de Psicanálise - o Legado de Freud e Lacan. Rio de Janeiro: Zahar, 1996.

LACAN, J. O Seminário- livro 11: os Quatro Conceitos Fundamentais da Psicanálise. Rio de Janeiro: Zahar, 1988 (1964).
LAZNIK, M. C. Os Efeitos da Palavra Sobre o Olhar dos Pais, Fundador do Corpo da Criança. In Agora Eu Era o Rei: os Entraves da Prematuridade. Daniele de Brito Wanderley (org.). Salvador, BA: Ágalma,1999.

LEVIN, E. A Infância em Cena: Constituição do Sujeito e Desenvolvimento Psicomotor. Petrópolis, RJ: Vozes, 1997.

MOLINA, S. A Estruturação Cognitiva na Criança Deficiente Mental e, Particularmente, na Criança com Síndrome de Down: um Enfoque a Partir da Interdisciplina e da Transdisciplina. In Escritos da Criança, $n^{\circ} 6$, Centro Lydia Coriat de Porto Alegre, 2001.

QUINET, A. A Descoberta do Inconsciente. RJ: Zahar, 2000.

RODULFO, R. O Brincar e o Significante: um Estudo Psicanalítico Sobre a Constituição Precoce. POA: Artes Médicas, 1990.

SZEJER, M. Feto, Recém-nascido e Pais Envolvidos na Linguagem. In Decifrando a Linguagem dos Bebês: Anais do Segundo Encontro Brasileiro Para o Estudo do Psiquismo Pré e Perinatal. São Paulo: ABREP - Associação Brasileira Para o Estudo do Psiquismo Pré e Perinatal, 1997.

WINNICOTT, D. A Preocupação Materna Primária. In Da Pediatria à Psicanálise: Obras Escolhidas. RJ: Imago, 2000 (1956). 